\title{
Nurses: Leading Change One Day at a Time
}

Katherine Chubbs, RN, MHS

Vice President and Chief Nursing Officer, Eastern Health, NL

President, Academy of Canadian Executive Nurses

Chair, Canadian College of Health Leaders, NL Chapter

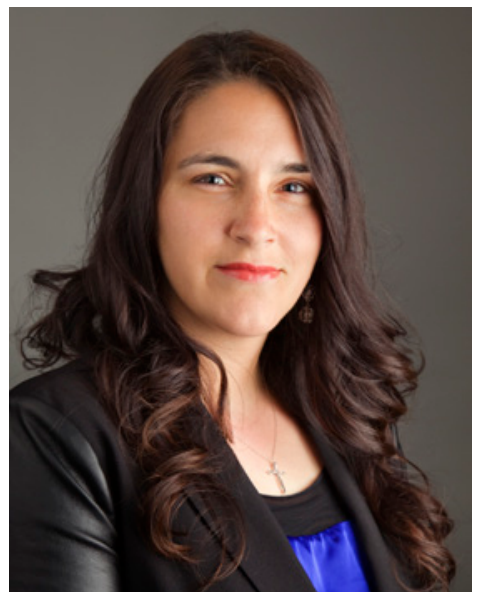

I know that sometimes it feels as though we stay status quo day after day or year after year, but actually so much has changed in nursing as a profession.

I occasionally hear a nurse say, "we tried that before and it did not work," or "been there, done that," but my thoughts always come back to "why?" Was it because the environment was not ready, the nurses were not ready, the patients or clients were not ready?

There has been enormous progress in nursing, and that progress did not come without change. The way I see it, we have two choices: to be a part of developing and leading the change, or to have change happen to us. I can think of many scenarios where change has happened to me in my career: changing scope of practice, changing workplace, changing position, changing organization and on and on. But in my experience, which is like that of many others, it is best to participate in making that change happen.

Nurses have been leading change and innovation likely for as long as the profession has existed. For example, some of you may not know that Florence Nightingale is credited with inventing the polar graph (Reference.com 2014). Not all nurses have to be inventors, but we do want our nurses to be involved in creating organizations that we can be proud to say deliver excellent evidencebased, high-quality care in safe environments.

Labour is a meaningful experience. Having to work harder at something makes it more meaningful - this is known as the IKEA effect (Norton 2009). The IKEA effect also demonstrates a limitation, namely, that labour leads to higher value only when the labour is fruitful (Norton 2009). Many nurses feel that they have to work harder now than ever before. Despite this, they continue to bring new ideas 
to the forefront and be involved. We know that when nurses are involved in the creation of something, they value it more.

A survey by researchers at Harvard University of nearly 600 senior executives identified engagement as the third highest success factor in their business, coming just slightly behind a high level of customer service (in our world, how we service our patients, clients, residents and their significant others) and effective communication (Harvard Business Review Analytic Services 2013). Business leaders recognize that an engaged workforce leads to innovation, productivity and bottom-line performance (Harvard Business Review Analytic Services 2013).

There is a valuable cycle evolving here. Nurses need to be involved in decisionmaking and change to make their work meaningful; meaningful work creates engagement; engagement increases innovation, productivity and performance; innovation leads to change.

As senior nursing leaders, we need to make this our approach. How can we help nurses to be involved? Encourage them to volunteer for any opportunities they see to improve service, and to speak up when they think change is needed. Inspire them to challenge the status quo and ask to try new things. We have to be open to new ideas and ways of doing our work. If something doesn't work, then we can try something else.

As nurses, we must love our work. We will never give it our best if we don't. As nurses, we must be at the forefront of change and innovation. We each have the power to influence our environments to make them more like what we want more what we will love. In fact, I would say we all have a responsibility to do that. Lastly, as nurses, we have knowledge. We are highly educated, skilled leaders who have the power to do great things.

At nearly 300,000 strong, Canadian nurses will lead our organizations to the places they need to be.

In the words of John Ruskin, "When love and skill work together, expect a masterpiece."

\section{References}

Harvard Business Review Analytic Services. 2013. The Impact of Employee Engagement on Performance. Retrieved May 13, 2014. <http://static.hbr.org/hbrg-main/resources/pdfs/comm/ achievers/hbr_achievers_report_sep13.pdf $>$.

Norton, M.I. 2009. The IKEA Effect: When Labor Leads to Love. Retrieved May 13, 2014. <http://hbr. org/web/2009/hbr-list/ikea-effect-when-labor-leads-to-love>.

Reference.com. 2014. What Did Florence Nightingale Invent? Retrieved May 13, 2014. < http:// answers.reference.com/wellness/misc/what_did_florence_nightingale_invent $>$. 